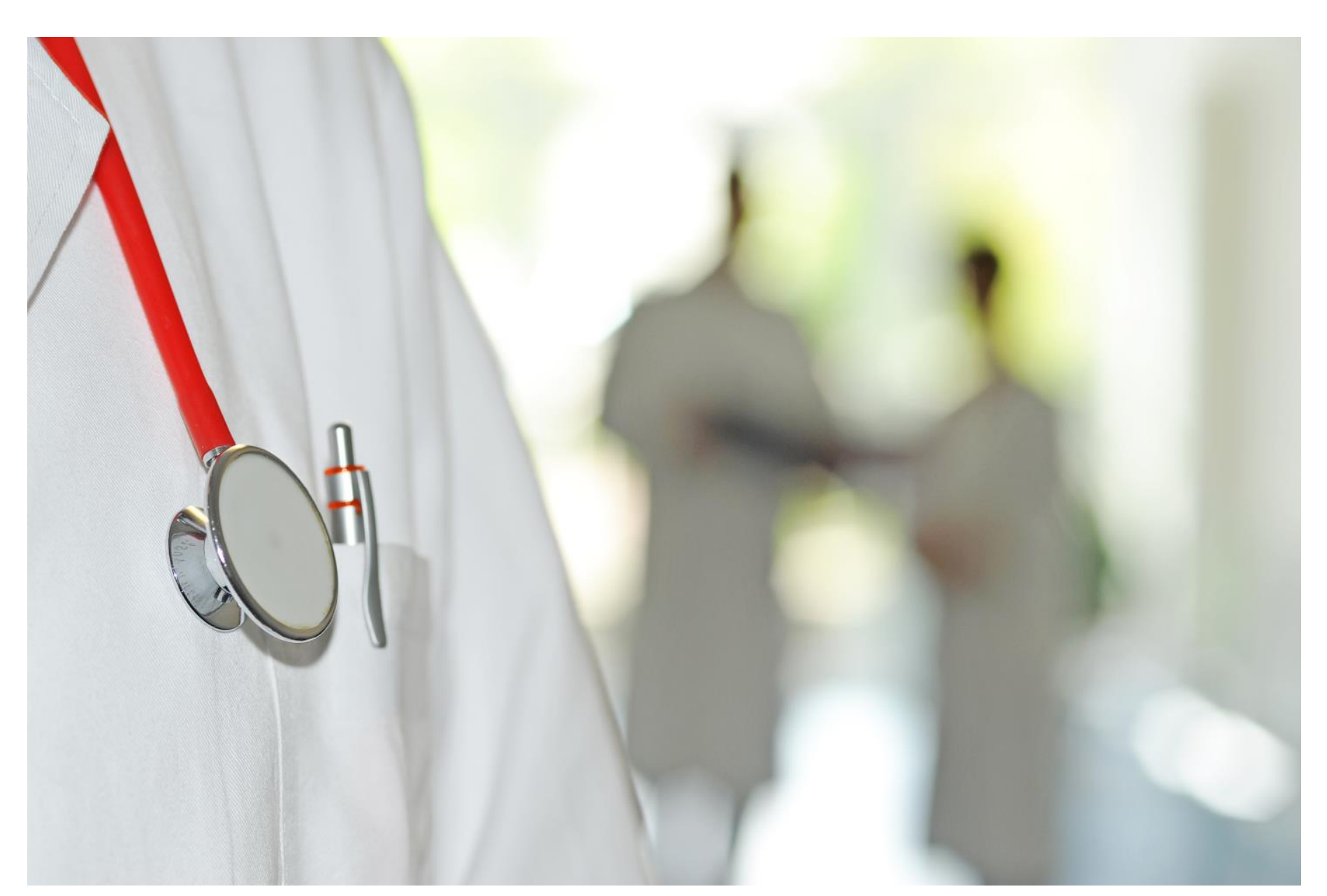

S. Kirana1, B. Eggert', K. Oberwelland ${ }^{2}$, G. Schürmann², J. Feldkamp'

1 Department of Internal Medicine, Endocrinology and Diabetology, Klinikum Bielefeld Mitte, Germany

2 Department of General and Visceral Surgery, Klinikum Bielefeld Mitte, Germany

\title{
High rate of malignant disorders in patients with primary hyperparathyroidism
}

\section{Introduction}

Some new data suggest a coincidence of differentiated thyroid carcinoma (DTH) in patients with primary hyperparathyroidism (pHPT). Rates of co-existing pHPT and thyroid pathology range from 20-67\%, with synchronous thyroid cancer occurring in 2 to $24 \%{ }^{1-3}$. Aim of the study is to evaluate the coincidence of thyroid cancer and concomitant diseases in our outpatients with pHPT.

\section{Methods \& Design}

Retrospective analysis of our patients $(n=267)$ with primary hyperparathyroidism from 2007 until 2011.

\section{Results}

Table 1. Demographic

\begin{tabular}{lr} 
Gender: Female & $210(78.85 \%)$ \\
\multicolumn{1}{c}{ Male } & $57(21.35 \%)$ \\
Treatment: & \\
Parathyroidectomy & $223(83.5 \%)$ \\
Conservative & $44(16.5 \%)$ \\
Age at parathyroidectomy: & \\
Female (mean in yrs) & 61 \\
Male (mean in vrs) & 55 \\
Clinical symptoms related to pHPT(n = 267) \\
Musculoskeletal pain \\
Gastrointestinal discomfort & $34.22 \%$ \\
Nephrolithiasis & $28.84 \%$ \\
Pathological fracture & $21.13 \%$ \\
& $10.27 \%$
\end{tabular}

In 257 patients Ultrasound examination showed uninodular goiter in 38 patients (14.8\%) and multinodular goiter was found in 117 patients (45.5\%).

Table 2. Histopathological findings of thyroid gland

We found $26.2 \%$ of patients had oncological disease, mostly DTH in 17 patients (7.62\%) and $34 \%$ suffered from endocrine disease (Figure 1).

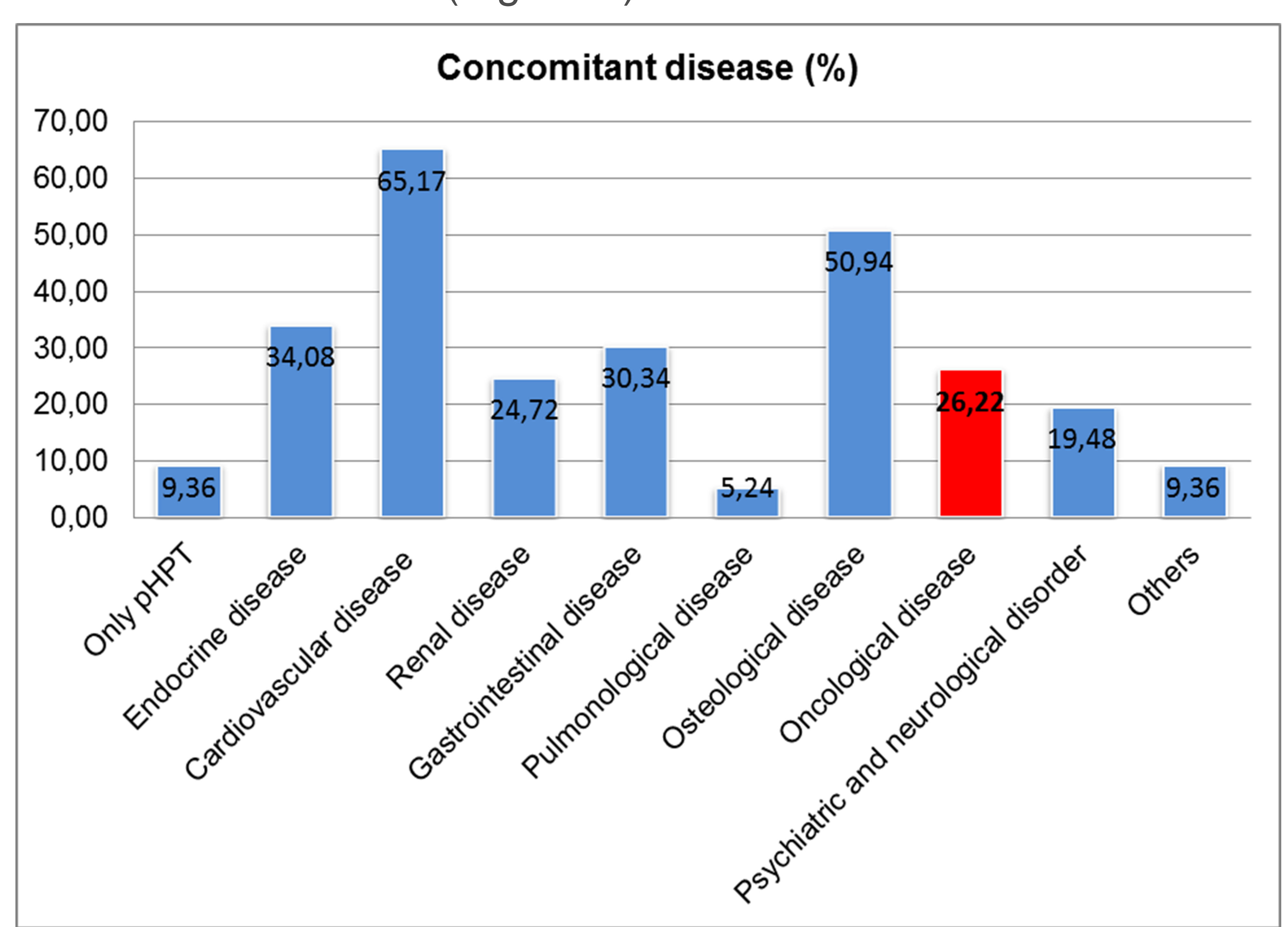

$\begin{array}{lr}\text { Follicular thyroid cancer } & 2(0.9 \%) \\ \text { Papillary thyroid cancer } & 14(6.27 \%) \\ \text { Medullary thyroid cancer } & 1(0.45 \%) \\ \text { C-Cell Hyperplasia } & 8(3.58 \%)\end{array}$

Endocrine disease was found in 91 patients. Most of them suffered from Hashimoto's thyroiditis (Figure 2).

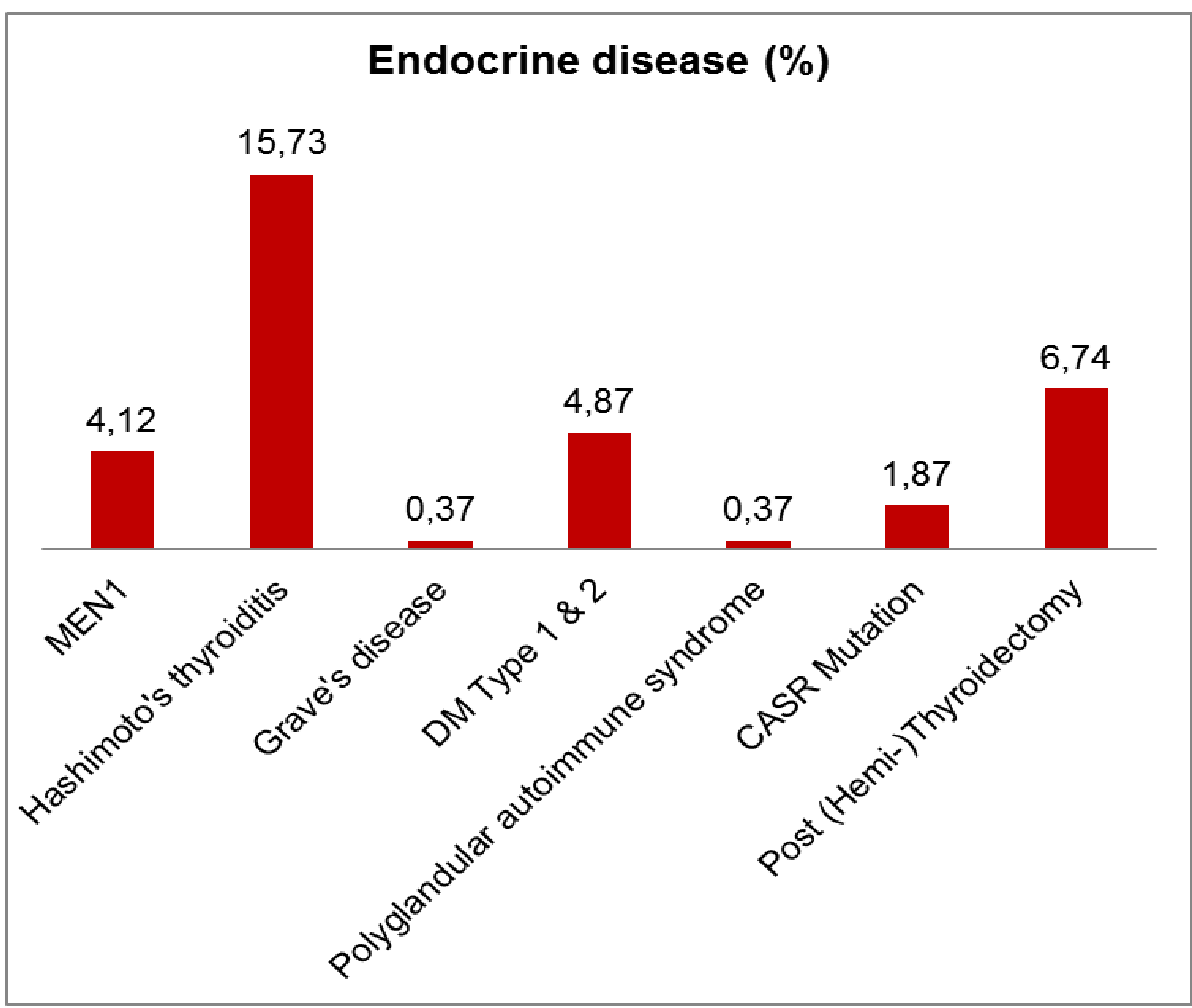

\section{Conclusion}

Thyroid cancer is not rare in patients with pHPT. Many of the patients have a history of other malignant diseases. Hashimoto's thyroiditis is a frequent thyroid disease in this group of patients. It still has to be investigated if there is a causal relationship between malignancy and hyperparathyroidism.

\section{References}

1. Arciero CA, Shiue ZS, Gates JD et al. Preoperative thyroid ultrasound is indicated in patients undergoing parathyroidectomy for primary hyperparathyroidism. J Cancer 2012; 3:1-6

2. Morita SY, Somervell H, Umbricht CB et al. Evaluation for concomitant thyroid nodules and primary hyperparathyroidism in patients undergoing parathyroidectomy or thyroidectomy. Surgery 2008; 144 (6): 862-866

3. Krause UC, Friedrich JH, Olbricht T, Metz K. Association of primary hyperparathyroidism and non-medullary thyroid cancer. Eur J Surg 1996; 162 (9): 685-689 